\title{
ARTIGO
}

d० https://doi.org/10.22481/praxis.v15i32.5060

\section{ESTADO, POLÍTICAS EDUCACIONAIS E TECNOLOGIAS FRENTE ÀS DEMANDAS DO CAPITALISMO CONTEMPORÂNEO}

\author{
STATE, EDUCATIONAL POLICIES AND TECHNOLOGIES TOWARD THE \\ CONTEMPORARY CAPITALISM DEMANDS
}

\section{ESTADO, POLÍTICAS EDUCACIONALES Y TECNOLOGÍAS FRENTE A LAS DEMANDAS DEL CAPITALISMO CONTEMPORÁNEO}

\author{
Maria Sueli Corrêa dos Prazeres \\ Universidade Federal do Pará - Brasil \\ Ilda Gonçalves Batista \\ Universidade Federal do Pará - Brasil
}

\begin{abstract}
Resumo: O presente artigo objetiva analisar o Estado e sua articulação na formulação das políticas educacionais voltadas a inserção das tecnologias digitais na educação. Faz-se um convite à reflexão, no sentido de promover, a compreensão de como o capital age, junto ao Estado, no processo de modelamento das políticas educacionais aos ideais econômicos e suas demandas a conjuntura educacional em face às intencionalidades de reestruturação econômico-produtiva. Adota-se uma análise crítica da tecnologia, considerada a partir do contexto histórico vivido e no conjunto da realidade social no qual é projetada, com o intuito de problematizar sua relação direta com a produção capitalista. Reflete-se sobre a trama de consolidação das TICs na educação demonstrando que a política de inclusão digital apresenta-se como um projeto capitalista de ajuste do Estado brasileiro às pressões políticas dos países hegemônicos para o qual as novas tecnologias atuam em benefício e para promoção do capital, numa busca incessante por novas formas de se solidificar economicamente.
\end{abstract}

Palavras-chave: Estado; Políticas Educacionais; Tecnologias de Informação e Comunicação.

\begin{abstract}
The present article aims to analyze the State and its articulation in the formulation of educational policies aimed at the insertion of digital technologies in education. It is an invitation to the reflection, in the sense to promote, the understanding of how capital acts, with the State, in the process of modeling educational policies to economic ideals and their demands to the educational situation in the face of the intentionalities of economic-productive of restructuring. A critical analysis of technology is adopted, considered started on the lived historical context and the social reality in which it is projected, intent to problematize your direct relation with capitalist production. It reflects on the plot of consolidation of ICT in education demonstrating that the politic of digital inclusion presents itself as a capitalist project of adjustment of the Brazilian State to the political pressures of the hegemonic countries for which the new technologies act for the benefit and for the promotion of the capital, in an incessant search for new ways to solidify economically.
\end{abstract}


Keywords: State; Educational Policies; Information and Communication Technologies.

Resumen: El presente artículo busca analizar al Estado y su articulación con la formulación de las políticas educacionales orientadas hacia la inserción de las tecnologías digitales en la educación. Se llama a la reflexión, en el sentido de promover la comprensión, sobre como actúa el capital junto al Estado en el proceso de ajuste de las políticas educacionales a los ideales económicos y sus demandas, la coyuntura educacional frente a las intenciones de reestructuración económico-productiva. Se adopta un análisis crítico de la tecnología, considerada a partir del contexto histórico vivido y en el conjunto de la realidad social hacia la cual es proyectada, con la intención de problematizar su relación directa con la producción capitalista. Se refleja sobre la trama de consolidación de las TICs en la educación demostrando que la política de inclusión digital se presenta como un proyecto capitalista de ajuste del Estado brasilero a las presiones políticas de los países hegemónicos, que se benefician con las nuevas tecnologías, y para la promoción del capital, en una búsqueda incesante de nuevas formas de consolidarse económicamente.

Palabras clave: Estado; Políticas Educacionales; Tecnologías de Información y Comunicación.

\section{Introdução}

$\mathrm{Na}$ atualidade, vivem-se intensas transformações frutos dos avanços científicos e tecnológicos dos últimos anos que remodelam a sociedade em ritmo acelerado. Designada de "Revolução Informacional ou da Informação" (CASTELLS, 1999), seria ela uma sequência histórica das revoluções sucessivas ocorrentes a partir da aceleração do processo e da veiculação da informação através da utilização da tecnologia. Para este autor uma das principais características dessa revolução tecnológica é a aplicação dos conhecimentos e das informações em um ciclo de realimentação cumulativo entre a inovação e o uso, no qual as novas tecnologias de informação e comunicação não são simplesmente ferramentas a serem aplicadas, mas sim processos a serem desenvolvidos.

Este trabalho problematiza que as novas tecnologias surgem em benefício e para promoção do capital, numa busca incessante por novas formas de se solidificar economicamente. Nesse processo, o Estado e o capital agem ideologicamente em defesa de sua manutenção e, assim, acabam por atribuir à educação e às tecnologias, condições necessárias para criar uma base mais sólida de produção, onde impera a busca por melhor qualificação para o mercado de trabalho com objetivo de gerar lucro e riqueza.

Assim, faz-se um convite à reflexão, no sentido de promover, a compreensão de como o capital age, junto ao Estado, no processo de modelamento das políticas educacionais aos ideais econômicos em face às intencionalidades de reestruturação econômico-produtiva. 
Parte-se da análise do contexto histórico de produção da sociedade capitalista e sua relação com o Estado enquanto produtores de demandas tecnológicas a conjuntura educacional na contemporaneidade.

\section{Relação estado-capital no delineamento das políticas educacionais}

O capital necessita de estruturas que viabilizem seu controle na sociedade, assim, a formação do Estado moderno "é uma exigência absoluta para assegurar e proteger permanentemente a produtividade do sistema" (MÉSZÁROS, 2011, p. 106), no qual suas práticas políticas atuam paralelamente a este, para favorecimento da dinâmica mutante de sua expansão e acumulação.

Dessa forma, no sistema capitalista, o Estado é levado a "mediar os interesses intercapitalistas e preservar o sistema como um todo" (FRIGOTTO, 2006, p. 100), para cumprir seu movimento e com isso alavancar seu crescimento. Para Frigotto (2006), este se assume como a própria forma do modo de produção capitalista enquanto gerenciador das suas relações dentro do movimento de acumulação, concentração e centralização do capital.

O Estado moderno constitui a "única estrutura corretiva compatível com os parâmetros estruturais do capital como modo de controle sociometabólico" (MÉSZÁROS, 2011, p. 107), protege legalmente a relação de forças estabelecidas, logo, sem essa estrutura jurídica não há como o capital manter sua eficiência econômica. Assim, como parte integrante da própria base material do capital, o Estado tem papel significativo na formação e consolidação de todas as grandes estruturas reprodutivas da sociedade:

O Estado moderno altamente burocratizado, com toda a complexidade de seu maquinário legal e político, surge da absoluta necessidade material da ordem metabólica do capital e depois, por sua vez - na forma de uma reciprocidade dialética - torna-se uma precondição essencial para a subsequente articulação de todo o conjunto. (MÉSZÁROS, 2011, p. 108).

Para Mészáros (2011), isso significa dizer que o Estado se afirma como pré-requisito indispensável para o funcionamento permanente do sistema do capital nas suas mais ínfimas relações, não impondo barreiras para sua expansão. Deste modo, o Estado assume papel totalizador e essencial nesse modelo de sociedade, pois deve sempre ajustar suas funções reguladoras em sintonia com a dinâmica do processo de reprodução socioeconômica, completando politicamente e reforçando a dominação do capital. 
É nesse sentido que o Estado adota, por meio de suas ações sociais (na educação, saúde, etc.), papel inexorável nas práticas de manutenção do capital, constituindo-se como requisito indispensável para sua produção e, no dizer de Mészáros (2011), um “microcosmo sociometabólico do capital", ou seja, uma unidade de reprodução socioeconômica, capaz de fazer funcionar, por meio de sua estrutura de comando e controle político, as estruturas reprodutivas do capital adaptando os diversos órgãos sociais que atuam sobre a regra deste sistema. Ball (2004) adverte que:

Cada vez mais, as políticas sociais e educacionais estão sendo articuladas e legitimadas explicita, direta e, muitas vezes exclusivamente em função do seu papel em aumentar a competitividade econômica por meio do desenvolvimento das habilidades, capacidades e disposições exigidas pelas novas formas econômicas da alta modernidade. (BALL, 2004, p. 1109).

Cabe destacar que nesse processo o Estado age como meio articulador dos interesses da economia capitalista enquanto poderoso instrumento de exploração política a favor dos grandes interesses do capital e, de uma classe, com o objetivo de remover as barreiras que dificultam seu desenvolvimento. Necessariamente, nesse cenário o Estado exerce uma dupla exploração "enquanto explora como qualquer outro capitalista, e enquanto aparelho repressivo e ideológico, efetiva uma exploração política a favor do capital no seu conjunto" (FRIGOTTO, 2006, p. 102), inserindo políticas que vislumbrem "permanecer estritamente dentro dos limites da perpetuação do domínio do capital como modo de reprodução social metabólica" (MÉSZÁROS, 2008, p. 26).

Para Ball (2004), na sociedade do capital as instituições do setor público estão sendo "repensadas" como oportunidades de lucros e, cada vez mais, o mundo dos negócios enfoca os serviços de educação como uma área em expansão, na qual lucros consideráveis devem ser obtidos. De modo geral, para que isso se efetive é imprescindível que o Estado em sua postura reguladora gere condições para o capital investir e proliferar.

Dessa forma, Barroso (2005) argumenta que a regulação realizada pelo Estado é vista como uma função essencial para a manutenção do equilíbrio de qualquer sistema (físico ou social) e está associada aos processos de retroação (positiva ou negativa). É ela que permite ao sistema, através dos seus órgãos reguladores, identificar as perturbações, analisar e tratar as informações relativas a um estado de desequilíbrio e transmitir um conjunto de ordens coerentes a um ou vários dos seus órgãos executores. Assim, a regulação está associada ao objetivo de consagrar à intervenção do Estado na condução das políticas públicas. 
O campo educacional, ao longo do processo histórico de desenvolvimento do capital, é permeado de interesses econômicos que se intensificam ainda mais quando empresas internacionais, como o Banco Mundial (BM) e o Fundo Monetário Internacional (FMI), "passam a operar de forma articulada no contexto da globalização econômica internacional para aprofundamento e a implementação de políticas que favoreçam a reprodução do capital" (HADDAD, 2008, p. 7), intervindo junto aos governos por meio da imposição de temáticas prioritárias e de uma abordagem economicista das políticas educacionais.

Com olhares voltados para o cenário econômico brasileiro as organizações internacionais adentram no campo educacional com o discurso de "investir para melhorar", porém utilizam-se da educação na lógica capitalista para acumular resultados positivos ao mercado. A educação, nesse sentido, perde sua dimensão enquanto bem público e passa a suprir as demandas das grandes empresas.

Barroso (2005) salienta que:

$\mathrm{Na}$ educação, se promovem, se discutem e se aplicam medidas políticas e administrativas que vão, em geral, no sentido de alterar os modos de regulação dos poderes públicos no sistema escolar (muitas vezes com recurso a dispositivos de mercado), ou de substituir esses poderes públicos por entidades privadas. (BARROSO, 2005, p. 726).

As orientações das políticas educacionais são realizadas sempre em complementaridade às orientações macroeconômicas estabelecidas, onde fica claro o interesse em fazer reforma educacional a partir da lógica neoliberal e a favor da prevalência da reprodução do grande capital. Dessa forma, pela ótica neoliberal a orientação é privatizar e com isso retirar a liberdade de escolha e participação do Estado para dar conta das demandas e necessidades do mercado.

Destarte a isso, as escolhas de políticas educacionais saem do poder do Estado e passam a ser definidas pela "mão invisível” do mercado em função de objetivos definidos pelo crescimento econômico. Para Barroso (2005) esse processo traduz-se, sobretudo, na subordinação das políticas de educação a uma lógica estritamente econômica ("globalização"); na importação de valores (competição, concorrência, excelência etc.) e modelos de gestão empresarial, como referentes para a "modernização" do serviço público de educação; na promoção de medidas tendentes à sua privatização.

Nesta perspectiva, assiste-se à tentativa de "criar mercados (ou quase-mercados) educativos transformando a ideia de 'serviço público' em 'serviços para clientes', onde o 'bem comum educativo' para todos é substituído por 'bens' diversos” (BARROSO, 2005, p. 
750). Logo, os produtos desse modelo geram a distribuição de serviços desiguais, uma educação para o rico e outra para o pobre, não havendo problema de criar um organismo de excluídos, pois seu objetivo central é adequar a educação a formar sujeitos para a demanda do mercado, negligencia-se qualquer tipo de escolha que vise o bem comum.

Em meio ao cenário da política neoliberal, a educação tornou-se um dos mais importantes investimentos do cerne capitalista, isso implicou em mudanças, porém estas negam os reais sentidos de uma sociedade igualitária e humanizadora, o que impera é a hegemonia de um mercado que incentiva o lucro, a luta de classes, uma educação enquanto mercadoria intensificando cada vez mais as premissas da teoria do capital humano (FRIGOTTO, 2010).

A educação passa a ser vista como um grande investimento e acaba sendo pretensão de negociação entre os capitalistas, os quais passam a atribuir novas demandas educacionais onde "os fatores sociais, políticos e econômicos que se estruturam a partir do processo de mundialização do capital são determinantes para a configuração da área educacional que, nesse contexto, tornou-se um grande mercado e o ensino uma mercadoria" (NASCIMENTO, 2011, p. 25).

Sendo assim, as políticas públicas educacionais constituídas a partir da manipulação do capital acabam colocando o problema da educação nas "costas" dos sujeitos omitindo o Estado dessa função, mas o certo é que muitas das medidas tomadas com relação às políticas educativas favorecem a introdução de uma lógica de mercado na prestação do serviço educativo, cujos efeitos contrariam claramente os princípios de uma formação de qualidade.

\section{A inserção da política brasileira de tecnologia no campo educacional}

Abordar a inserção das Tecnologias de Informação e Comunicação (TIC) na educação pressupõe pensar, com base nos princípios da sociedade capitalista, qual seu papel no processo de formação dos sujeitos, uma vez que, ao longo da história a educação é alçada como instrumento de proliferação dos interesses de classe onde os processos educativos são utilizados na produção e reprodução das relações sociais. Para isso, é necessário pensá-la a partir do desenvolvimento histórico da sociedade capitalista reconhecendo as condições de sua produção e compreendendo suas principais manifestações.

A educação, ao longo do processo histórico da sociedade capitalista, é entendida segundo Frigotto (2006) como algo não meramente instrumental, mas decisivo do ponto de 
vista do desenvolvimento da economia. Nesse panorama, a teoria do capital humano ${ }^{1}$ se configurou como um dos elementos constitutivos e reforçadores da tendência tecnicista de educação no qual sua subordinação significa torná-la funcional ao sistema capitalista, isto é, colocá-la a serviço dos interesses da classe dominante, uma vez que, qualificando a força de trabalho, o processo educativo concorreria para o incremento da produção da mais-valia, reforçando, em consequência, as relações de exploração.

Deste modo, "a educação, quando apreendida no plano das determinações sociais e, portanto, ela mesma constituída e constituinte destas relações, apresenta-se historicamente como um campo de disputa hegemônica" (FRIGOTTO, 2010, p. 27) e passa a definir-se como uma técnica de preparar recursos humanos para o processo de produção em prol dos interesses de classes.

Para Frigotto (2010) este cenário vislumbra duas vertentes antagônicas de formação humana. Na perspectiva das classes dominantes a educação objetiva habilitá-los técnica, social e ideologicamente para o trabalho a fim de responder as demandas do capital. $\mathrm{Na}$ perspectiva dos grupos sociais, especialmente para a classe trabalhadora, a educação define-se como o desenvolvimento de potencialidades que lhes permitam adquirir conhecimentos para satisfazer seus interesses e necessidades. Ou seja, expõe a existência de uma escola dualista em defesa de um ensino disciplinador e adestrador para os filhos dos trabalhadores e formativo para os filhos das classes dirigentes.

Isto evidencia que "a educação é o processo pelo qual a sociedade forma seus membros à sua imagem e em função de seus interesses" (VIEIRA PINTO, 1993, p. 29), assim, "a educação e a formação humana terão como sujeito definidor as necessidades, as demandas do processo de acumulação de capital sob as diferentes formas históricas de sociabilidade que assumir" (FRIGOTTO, 2010, p. 33).

Portanto, a educação pode ser compreendida como uma arma de coerção usada pelo capital, por via do Estado, para manter sua estrutura. É usada como meio de subordinação ao mercado e a sua adaptabilidade e funcionalidade, quando na verdade deveria ser empregada como elo mediador na formação de sujeitos mais críticos e reflexivos sobre suas reais necessidades. A educação deveria promover a qualificação humana para o:

\footnotetext{
${ }^{1}$ A ideia-chave é de que a um acréscimo marginal de instrução, treinamento e educação, corresponde um acréscimo marginal de capacidade de produção. Ou seja, a ideia de capital humano é uma "quantidade" ou um grau de educação e de qualificação, tomado como indicativo de um determinado volume de conhecimentos, habilidades e atitudes adquiridas, que funcionam como potencializadoras da capacidade de trabalho e de produção (FRIGOTTO, 2010, p. 44).
} 
[...] desenvolvimento de condições físicas, mentais, afetivas, estéticas e lúdicas do ser humano (condições omnilaterais) capazes de ampliar a capacidade do trabalho na produção dos valores de uso em geral como condição de satisfação das múltiplas necessidades do ser humano no seu devenir histórico. (FRIGOTTO, 2010, p. 34).

Porém, as práticas educativas ao serem subordinadas aos preceitos do capital acabam adquirindo interesses diversos e antagônicos para as diferentes classes tendo como condição indispensável a sua estruturação "a necessidade de que a reprodução da força de trabalho seja moldada, forjada, fabricada para a disciplina e subordinação das novas relações de produção" (FRIGOTTO, 2010, p. 36), assumindo-se como prática social de produção econômica, ou seja, capital humano.

A disseminação da teoria do capital humano é lançada como crença de mágica solução das desigualdades sociais entre os países desenvolvidos e os subdesenvolvidos representando dominantemente a visão e os interesses do capitalismo integrado ao grande capital. Isso perdura ao longo da histórica relação entre trabalho-educação e se intensifica a partir da década de 90 quando é incorporada ao debate da tecnologia.

O surgimento das novas tecnologias permite identificar uma problemática que se expõe como desafio aos processos educativos, pois estas se inserem ocasionando mudanças sobre o trabalho e a qualificação humana e refletem, na maioria das vezes, o ideário da sociedade capitalista, o qual acaba por assumir novas formas e demandas oriundas da lógica do mercado. Este desafio se apresenta no plano político-ideológico denominado de Sociedade da Informação ou do Conhecimento (dentre outros inúmeros termos usados) ambas embasadas no acesso "global” a informação, conhecimento e desenvolvimento.

A expressão "Sociedade da Informação" surge no contexto da pós-modernidade, mais precisamente na década de 1970, a partir das discussões sobre o que seria a "sociedade pósindustrial" e juntamente com o termo "globalização" apresentando novas condições para o processamento de informação. Essa reformulação social não passa de uma reorganização do capital em meio as suas crises, por vezes cíclicas, na busca de instabilidade financeira e tem como atributos chaves a informação e o conhecimento enquanto mecanismos de promoção do desenvolvimento técnico-científico.

Para Pimenta (2014) as origens e causas desta sociedade se alicerçam em dois tipos de desenvolvimento interdependentes: o desenvolvimento econômico a longo prazo e a mudança tecnológica. Ambos estão estritamente ligados à reestruturação do capital para o qual as novas tecnologias de informação e comunicação surgem como instrumentos possibilitadores do processo de globalização e ampliação do sistema. 
$\mathrm{O}$ fim do século $\mathrm{XX}$ trouxe à tona uma nova reorganização dos modos de produção e negócios e, por consequência, da economia, da sociedade e da política, de acordo com Pimenta (2014). Dentro dessa ordem econômico-social, sob a égide da Sociedade da Informação, defende-se a busca por uma nova qualidade da educação e a formação com princípios alçados aos requisitos e demandas do mercado para o qual é fundamental uma eficiente qualificação para o trabalho que vislumbre "uma formação geral e abstrata, que prepara sujeitos polivalentes, flexíveis e participativos” (FRIGOTTO 2010, p. 59).

A exigência dessa sociedade é que:

A informação se traduza em ativo estratégico, diferencial competitivo, recurso gerencial e vetor de desenvolvimento. E esta exigência se sustenta no uso intensivo das tecnologias de informação e comunicação, que prometem eliminar os marcadores de fronteiras entre os conectados e os desconectados, com a mesma ênfase que se propõem a eliminar as barreiras entre a ignorância e o saber. (PIMENTA, 2014, p. 38).

No bojo da reestruturação produtiva do capital, as novas tecnologias de informação e comunicação surgem produzindo e acelerando os processos comunicativos e com a perspectiva de gerar ou transformar informação em conhecimento, em prol do aumento da produtividade do sistema econômico, pois este a priori é compreendido como o principal fator de produção técnico-científica e produtor de desenvolvimento. Dessa forma, este paradigma social deixa claro que se trata "simplesmente de uma nova fase do capitalismo, em que as tecnologias de informação adquirem uma relevância fundamental” (BOLAÑO, 2000, p. 127), atribuindo caracteres utilitaristas a informação e ao conhecimento sem perder sua coerência interna de busca permanente por expansão, acumulação e concentração.

Para Mészáros (2011), o sistema capitalista é a mais poderosa estrutura "totalizadora" de controle onde tudo deve se ajustar a ela, inclusive os seres humanos, e provar sua viabilidade produtiva. $\mathrm{O}$ autor destaca este sistema como algo globalmente dominante que se sobrepõe a tudo e a seus próprios critérios de viabilidade, sempre a favor do grande capital. É com base nesse argumento que este caracteriza o sistema como um movimento incontrolável "totalizador irrecusável e irresistível, não importa quão repressiva tenha de ser a imposição de sua função totalizadora" (MÉSZÁROS, 2011, p. 96).

O Brasil, por não está fora do contexto massacrante do capitalismo e da "globalização", com sua economia presa a um círculo vicioso, vive administrando sempre tensas e paradoxais relações entre a mão pesada do Estado e a "mão invisível do mercado" (PIMENTA, 2014, p. 47), que a partir da perspectiva neoliberal acaba por disseminar a 
democratização do acesso à informação e a produção de conhecimentos reduzidos à questão econômica e guiados pela ênfase nas habilidades e competências para o mercado de trabalho.

Considerando a relação orgânica entre Estado e capital, no conjunto das políticas neoliberais, o primeiro usa o aparato tecnológico como um mecanismo ideológico, para implementar o ajuste estrutural impostos pelos organismos internacionais e o segundo o faz com a finalidade de recompor suas taxas de acumulação, garantir o controle do processo produtivo e explorar novos nichos de mercado (NASCIMENTO, 2011, p. 30-31).

Neste cenário o "Estado viu-se obrigado a se adequar ao novo paradigma técnico e econômico, à liberalização dos mercados nacionais e à "globalização" da economia, passando, então, a assumir um papel redimensionado nos planos produtivo e administrativo" (PIMENTA, 2014, p. 40). Assim, o Brasil, fortemente envolvido pela bolha da "globalização", no início dos anos 1990, passou a adotar políticas neoliberais, com base na flexibilização do mercado.

O Brasil para se inserir nesse novo panorama socioeconômico da Sociedade da Informação apresenta o Programa Sociedade da Informação - SOCINFO, publicado no Livro Verde, no ano de 2000 apoiando-se no novo paradigma de informação como bem econômico e de informação estratégica para o desenvolvimento (PIMENTA, 2014). O SOCINFO é na verdade a primeira iniciativa do governo brasileiro em definir um projeto estratégico que pudesse integrar e coordenar o desenvolvimento e a utilização de serviços avançados de computação, comunicação e informação.

Os Livros Verdes são, pois, o resultado da discussão de iniciativas mundiais voltadas para a construção de uma sociedade da informação para qual o advento é o fundamento de novas formas de organização e de produção em escala mundial, redefinindo a inserção dos países na sociedade internacional e no sistema econômico mundial. Segundo este documento caberia ao sistema político promover políticas de inclusão social, para que o salto tecnológico tenha paralelo quantitativo e qualitativo nas dimensões humana, ética e econômica (TAKAHASHI, 2000).

A chamada "alfabetização digital" é elemento-chave nesse quadro. Porém, isso ocorre somente no papel, pois o que se vê, principalmente nos países periféricos, é o aumento intenso da exclusão digital ocasionada pela tão propagada "globalização", uma vez que, apesar de se apresentar como um acontecimento muito benéfico ao desenvolvimento social dos países, esse fenômeno surge sobre o domínio do capital provocando mudanças em prol dos interesses dos países desenvolvidos deixando os demais à mercê das desigualdades e da exploração. 
Para Prazeres (2016) em pleno século XXI, é impossível afirmar que se vive na tão divulgada sociedade, por ser esta uma ideologia produzida pelo capitalismo e por preservar o modelo de exclusão, que caminha no sentido oposto ao da proposta de incluir a todos. Assim, para esta autora a inclusão digital se apresenta como uma "ilusão", pois é estruturada com o propósito de atender às demandas do mercado capitalista na qual as políticas adotadas nessa direção apenas acrescentam pequenas mudanças, não intervindo na estrutura mais ampla, e contribuindo com a reprodução da estrutura de dominação e legitimação de valores dominantes.

Dessa forma, as políticas de inserção das tecnologias na educação seguem da trama dos preceitos neoliberais do Estado capitalista na qual a "dinâmica estrutural da sociedade capitalista é determinante na formulação de concepções e orientações para o ensino" (NASCIMENTO, 2011, p. 25). Para este autor, o uso das tecnologias de informação e comunicação, em um cenário de novas demandas educacionais, determinadas pela mundialização do capital, está acompanhado da própria noção do que se deseja educar, de qual é a função das instituições de ensino e de que sujeito se pretende formar.

Nesta instância "as políticas públicas sociais caminham no sentido de manutenção da ordem estabelecida, uma vez que não rompem com as estruturas de reprodução das desigualdades" (PRAZERES, 2016, p. 62), na qual o Programa Brasileiro da Sociedade da Informação se "apresentou como mais um projeto capitalista de ajuste do Estado brasileiro às pressões dos países hegemônicos, cujo principal objetivo era inserir o país na economia mundial globalizada" (PIMENTA, 2014, p. 9).

Deste modo, Nascimento (2011) afirma que:

[...] a sociedade do conhecimento e sua sociabilidade pautada nas novas tecnologias de informação e comunicação, não representam uma ruptura da configuração capitalista, não delineia novas relações classistas, mas tem como objetivo principal operar ideologicamente na construção do fetichismo tecnológico que reconfigura o modus operandi da produção capitalista industrial e estabelece uma nova era social e educacional centrada nas possibilidades de construção de uma cidadania 'global', 'em rede', viabilizada pelo poder do acesso à informação e pela possibilidade imensurável de comunicação. (NASCIMENTO, 2011, p. 69).

Nesta perspectiva, para este autor, há a inserção de uma noção fetichista de tecnologia engendrada pelo Estado e determinada pelo capital que articula o uso da inovação tecnológica às suas finalidades utilizando-a como preceito de formação para necessária inserção no 
mundo do trabalho. Ou seja, tomam a tecnologia como uma variável, um fator independente e autônomo aos interesses de classe e às relações de poder.

$\mathrm{O}$ autor acentua ainda que a sociabilidade capitalista ancorada nas novas tecnologias e no fetichismo tecnológico determinados pelo capital em um contexto geral, no nível das relações sociais e de produção, se materializa em contextos particulares, como no caso das políticas públicas educacionais, e é determinada por um fenômeno muito mais complexo, o da reestruturação do processo de acumulação capitalista para fins de reprodução do capital.

\section{Considerações finais}

A relação entre a sociedade e a tecnologia não se apresenta de forma tranquila, isso por que, apesar dos avanços obtidos pelas sucessivas revoluções tecnológicas, não foi possível garantir melhoria de qualidade de vida a amplos segmentos sociais que ainda se encontram excluídos, vivendo às margens dos bens sociais e tecnológicos. Assim, é preciso estudar esse impacto sem perder de vista todos os efeitos causados por essa interatividade.

De tal modo, infelizmente o acesso aos bens tecnológicos, ainda, é restrito e não garante a inclusão de todos, pois, a possibilidade de acesso tecnológico trava no embate riqueza-pobreza. O desafio do desenvolvimento tecnológico depende do potencial de desenvolvimento socioeconômico, das lutas individuais e coletivas pelo acesso igualitário aos bens sociais e tecnológicos. Em nosso país, lamentavelmente, o que se observa é uma injusta distribuição de renda que influência diretamente no acesso aos recursos tecnológicos, apesar da tão propagada defesa da introdução das tecnologias em todos os setores públicos.

Sob essa perspectiva, as políticas de educação, pensadas para incluir digitalmente segmentos marginalizados da sociedade, são insuficientes, pois inserem insumos tecnológicos na escola priorizando aspectos meramente técnicos ou tecnológicos. Assim, argumenta-se a necessidade dessas políticas serem repensadas para proporcionar uma formação que não preconize somente demandas do mercado, mas ações que desenvolvam a formação integral do indivíduo e ao mesmo tempo estejam acima das lutas de classes e dos interesses do mercado para que sejam destinadas aos interesses do indivíduo e da sociedade.

Alertamos, a partir de Vieira Pinto (2005), que a tecnologia não deve ser compreendida como causa, mas mediação, onde as forças de ascensão nos países pobres devem tomar consciência e de que precisam lançar mão para lutar contra velhas estruturas de relações sociais. Paradoxalmente, exaltar a tecnologia significaria retardar seu efeito libertador a ponto de fazer dela uma nova mitologia, com sua numerosa procissão de 
idólatras. A tecnologia, desse modo, tem que ser um meio para nossas relações dentro do modelo capitalista, para transformá-lo, e não para mantê-lo.

A análise do autor sobre as relações entre interesses econômicos e determinado padrão tecnológico aponta para a necessidade de se estar atento, no campo pedagógico, ao fato de que, ao se copiar acriticamente os projetos e modelos adotados no campo industrial, interesses e lógicas próprias estão sendo incorporados. Nem sempre a lógica da indústria é a mesma da educação, os interesses podem ser diferentes e, fundamentalmente, a natureza dos resultados e o tempo em que eles ocorrem podem ser diferenciados. Nessa leitura, toda tecnologia consiste em uma determinada concepção do significado e do valor das ações humanas.

Logo, a educação que interessa à classe trabalhadora não é a que inseri insumos tecnológicos para o uso técnico da tecnologia, mas aquela que possibilita a reflexão, que permite o sujeito se enxergar enquanto produtor de valor, que politiza, que desaliena, que forma para a vida em qualquer sociedade. Essa proposta ainda não se encontra em nenhuma estrutura de ensino pensada pelo Estado, considerando seu caráter neoliberal, encontra-se nos movimentos sociais, nas comunidades de base, nos partidos políticos e nas práticas pedagógicas de professores comprometidos com a transformação social.

\section{REFERÊNCIAS}

BALL, S. J. Performatividade, privatização e o estado do bem estar. Educação \& Sociedade, v. 25, no. 89, PP. 1105-1126, dez. 2004.

BARROSO, João. O Estado, a educação e a regulação das políticas públicas. IN:

Educação e Sociedade, Campinas, vol. 26, n. 92, p. 725-751, Especial, Out, 2005, p. 725-751.

BOLAÑO, César Ricardo Siqueira. Sociedade da informação: reestruturação capitalista e esfera pública global. Araraquera/SP, v. 8, n. 00, p. 93-128, 2000. Disponível em <https://seer.fclar.unesp.br/estudos/article/viewFile/834/695> Acesso 19 jul. 2017 às $17 \mathrm{~h} 45 \mathrm{~min}$.

CASTELLS, Manuel. A sociedade em rede. Vol. 1. São Paulo: Paz e Terra, 1999.

FRIGOTTO, Gaudêncio. A produtividade da escola improdutiva: um (re) exame das relações entre educação e estrutura econômico-social capitalista. $8^{a}$ edição. São Paulo: Cortez, 2006.

FRIGOTTO, Gaudêncio. Educação e a crise do capitalismo real. $6^{\text {a }}$ edição. São Paulo: Cortez, 2010. 
HADDAD, Sérgio (Org.) Banco Mundial, OMC e FMI. O Impacto nas Políticas Educacionais. São Paulo: Cortez Editora, 2008.

MÉSZÁROS, István. A educação para além do capital. $2^{a}$ Edição. Tradução de Isa Tavares. São Paulo: Boitempo, 2008.

MÉSZÁROS, István. Para além do capital: Rumo a uma teoria da transição. Tradução de Paulo Cezar Castanheira e Sérgio Lessa. São Paulo: Boitempo, 2011.

NASCIMENTO, Alberico Francisco. A Educação a Distância e fetichismo tecnológico: Estado e Capital no projeto de Ensino Superior no Brasil. 2011. 233 f. Tese (Doutorado em Políticas Públicas) - Universidade Federal do Maranhão, São Luís, 2011.

PIMENTA, Márcia Teresa da Rocha. A política de inserção do Brasil na "Sociedade da informação": uma avaliação política do Programa Sociedade da Informação - SOCINFO. 2014. 222 f. Tese (Doutorado em Políticas Públicas) - Universidade Federal do Maranhão, São Luís, 2014.

PRAZERES, Maria Sueli Corrêa dos. O Programa Navega Pará como política pública de inclusão digital: implicações nas escolas públicas do Estado Pará, 2016. 274 fls. Tese (Doutorado em Educação) - Universidade Estadual de Ponta Grossa, Ponta Grossa, 2016.

TAKAHASHI, Tadeu (Org.). Sociedade da Informação no Brasil: Livro Verde. Brasília: Ministério da Ciência e da Tecnologia, 2000.

VIEIRA PINTO, Álvaro. Sete lições sobre educação de adultos. $8^{\text {a }}$ Edição. São Paulo: Cortez, 1993.

VIEIRA PINTO, Álvaro. O conceito de tecnologia. Vol. 1. São Paulo: Contraponto, 2005.

\section{SOBRE AS AUTORAS}

\section{Maria Sueli Corrêa dos Prazeres}

Doutora em Educação pela Universidade Estadual de Ponta Grossa (UEPG). Docente do Programa de Pós-graduação em Educação e Cultura, da Universidade Federal do Pará (UFPA). Membro associado da Red Latinoamericana de Estudios Epistemológicos en Política Educativa (ReLePe). E-mail: suelicorrea@ufpa.br

\section{Ilda Gonçalves Batista}

Mestre em Educação e Cultura pela Universidade Federal do Pará (UFPA). Professora da Rede Municipal de Parauapebas. Membro associado no Grupo de Pesquisa Trabalho, Tecnologia e Educação do Campo. E-mail: ildagoncalves92@ yahoo.com.br 